\title{
Desempenho agronômico de canola em diferentes espaçamentos entre linhas e densidades de plantas
}

\author{
Taiane Pettenon Bandeira(1), Geraldo Chavarria( ${ }^{(1)}$ e Gilberto Omar Tomm ${ }^{(2)}$
}

\begin{abstract}
(1)Universidade de Passo Fundo, Faculdade de Agronomia e Medicina Veterinária, BR-285, São José, Caixa Postal 611, CEP $99001-970$ Passo Fundo, RS. E-mail: taia_tai@hotmail.com, geraldochavarria@upf.br (2)Embrapa Trigo, BR-285, Km 294, Caixa Postal 451, CEP 99001-970 Passo Fundo, RS. E-mail: gilberto.tomm@embrapa.br
\end{abstract}

\begin{abstract}
Resumo - O objetivo deste trabalho foi avaliar o desempenho agronômico da canola em diferentes espaçamentos entre linhas e densidades de plantas. O delineamento experimental de blocos ao acaso foi utilizado com quatro repetições, em arranjo de parcelas subdivididas. As parcelas foram constituídas pelo espaçamento entre linhas $(17,34,51$ e $68 \mathrm{~cm})$, e as subparcelas pelas densidades de plantas $(15,30,45$ e 60 plantas por metro quadrado). Os experimentos foram conduzidos em 2011 e 2012. Avaliações foram feitas quanto a: número de ramos secundários, terciários e quaternários; número de síliquas nos ramos primários, secundários, terciários e quaternários; número de síliquas por planta; número de grãos por planta; massa de mil grãos; rendimento de grãos; produção biológica aparente por planta; produção de palha e de grãos por planta; e índice de colheita. Os maiores números de ramos, síliquas por planta, e grãos por planta, bem como a maior produção de massa total na planta foram obtidos ao se utilizar a densidade de 15 plantas por metro quadrado. O maior rendimento de grãos por área é obtido ao se utilizar o espaçamento de $17 \mathrm{~cm}$ entre linhas e a densidade de 45 plantas por metro quadrado.
\end{abstract}

Termos para indexação: Brassica napus, componentes do rendimento, densidade de plantas, produtividade de grãos.

\section{Agronomic performance of canola at different row spacing and plant densities}

\begin{abstract}
The objective of this work was to evaluate the agronomic performance of canola at different row spacing and plant densities. A randomized complete block design was used with four replicates in a split-plot arrangement. The plots consisted of row spacing $(17,34,51$ and $68 \mathrm{~cm}$ ), and subplots consisted of plant densities (15, 30, 45 and 60 plants per square meter). The experiments were carried out in 2011 and 2012. Evaluations were done for: number of secondary, tertiary, and quaternary branches; number of pods on primary, secondary, tertiary, and quaternary branches; number of pods per plant; number of grains per plant; thousand grain weight; grain yield; apparent biological yield per plant; straw and grain yield per plant; and harvest index. The largest numbers of branches, pods per plant, and grains per plant, as well as the highest total mass of plants were obtained when using plant density of 15 plants per square meter. The highest grain yield per area is obtained when using $17 \mathrm{~cm}$ row spacing and plant density of 45 plants per square meter.
\end{abstract}

Index terms: Brassica napus, yield components, plant density, grain yield.

\section{Introdução}

A canola (Brassica napus L.) é uma das oleaginosas mais importantes na agricultura mundial e uma das principais fontes de óleo vegetal comestível, além de ser uma importante fonte de energia renovável, por sua utilização na produção de biodiesel (Tan et al., 2009).

As áreas de canola no Brasil se concentram principalmente no Rio Grande do Sul e Paraná, mas também há algumas lavouras no Mato Grosso do Sul, Minas Gerais e Santa Catarina. O rendimento de grãos para a safra 2011/2012 foi estimado em cerca de $1.226 \mathrm{~kg} \mathrm{ha}^{-1}$ e, para a safra 2012/2013, em cerca de $1.381 \mathrm{~kg} \mathrm{ha}^{-1}$. O Rio Grande do Sul é o principal produtor dessa cultura, com área semeada em 2011/2012 de 33.500 ha e, em 2012/2013, de 28.685 ha. O rendimento estimado no Rio Grande do Sul foi de $1.287 \mathrm{~kg} \mathrm{ha}^{-1}$ na safra 2011/2012 e, na safra 2012/2013, de $1.082 \mathrm{~kg} \mathrm{ha}^{-1}$ (Tomm, 2013).

A demanda brasileira pelo cultivo fez crescer o incentivo à pesquisa da canola. Entretanto, informações técnico-científicas referentes ao manejo da canola no Brasil ainda são limitadas. Muitos produtores rurais estão apenas iniciando o seu cultivo, e informações mais precisas de práticas de manejo (Battisti et al., 
2013), entre elas, o espaçamento entre linhas e a densidade de plantas para as diversas regiões precisam ser obtidas e difundidas.

A modificação no arranjo de plantas, por meio de variações no espaçamento entre linhas ou entre plantas dentro das linhas pode ser uma alternativa para se alcançar maior produtividade de grãos de canola (Krüger et al., 2011). No entanto, as culturas somente expressam o seu potencial produtivo máximo (produção de grãos e folhas) em condições de ausência de fatores de estresse e com a máxima interceptação de radiação solar, o que justifica a necessidade do ajuste adequado do dossel conforme a espécie, a cultivar, e os demais fatores que podem contribuir em sua expressão morfológica (Argenta et al., 2001).

Os componentes ligados diretamente ao rendimento de grãos em canola são: o número de síliquas por planta, o número de grãos por síliqua, a massa de um grão e o número de plantas por unidade de área (Canola Council of Canada, 2012). No entanto, há componentes que influenciam indiretamente o rendimento, como o número de ramos primários, secundários e terciários e o comprimento dos ramos. Em canola, o principal componente de rendimento é o número de flores que se traduzem em síliquas. O número de síliquas é um fator de extrema importância, pois determina a produção de grãos de canola (Gan et al., 2004).

O objetivo deste trabalho foi avaliar o desempenho agronômico de canola, cultivada em diferentes espaçamentos entre linhas e densidades de plantas.

\section{Material e Métodos}

Os experimentos foram realizados em campo, na área experimental da Faculdade de Agronomia e Medicina Veterinária, da Universidade de Passo Fundo,

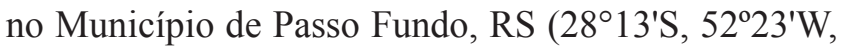
a aproximadamente $687 \mathrm{~m}$ de altitude), nos anos agrícolas de 2011 e 2012. Os dados meteorológicos das temperaturas máxima, média e mínima e da precipitação pluvial mensal durante a condução dos experimentos estão apresentados na Figura 1.

O solo das áreas experimentais é classificado como Latossolo Vermelho distrófico típico (Santos et al., 2006). A análise química do solo, na camada de $0-20 \mathrm{~cm}$ apresentou os seguintes valores: $\mathrm{P}, 16,3 \mathrm{mg} \mathrm{dm}^{-3}$; $\mathrm{K}, 138 \mathrm{mg} \mathrm{dm}^{-3} ; \mathrm{Al}, 0,3 \mathrm{cmol}_{\mathrm{c}} \mathrm{dm}^{-3} ; \mathrm{pH}$ em água, 5,4; $\mathrm{V}, 53 \%$ e S, $15 \mathrm{mg} \mathrm{dm}^{-3}$, na safra 2011/2012. Na safra
2012/2013, os valores foram: P, 28,2 $\mathrm{mg} \mathrm{dm}^{-3}$; $\mathrm{K}$, $175 \mathrm{mg} \mathrm{dm}^{-3}$; $\mathrm{Al}, 0,1 \mathrm{cmol}_{\mathrm{c}} \mathrm{dm}^{-3} ; \mathrm{pH}$ em água, 5,4; $\mathrm{V}$, $53 \%$ e S, $14 \mathrm{mg} \mathrm{dm}^{-3}$.

Anteriormente à implantação do experimento da safra 2011/2012, a área estava ocupada com a soja no verão e o trigo no inverno. Na safra 2012/2013, a área havia sido ocupada com soja no verão e azevém no inverno. As duas áreas utilizadas têm sido conduzidas em sistema de semeadura direta há mais de cinco anos.

No ano de 2011, a semeadura foi efetuada em 19 de abril, com aplicação de adubação de base de $300 \mathrm{~kg} \mathrm{ha}^{-1}$, da formulação 05-25-25 de N- $\mathrm{P}_{2} \mathrm{O}_{5}-\mathrm{K}_{2} \mathrm{O}$, e adubação de cobertura de $100 \mathrm{~kg} \mathrm{ha}^{-1}$ de $\mathrm{N}$ no estádio de quatro folhas verdadeiras (V4), conforme recomendação de análise de solo necessária ao desenvolvimento da cultura. A emergência das plantas ocorreu em 30 de abril. No ano de 2012, a semeadura foi realizada no dia 8 de maio. A adubação de base à semeadura foi realizada com $300 \mathrm{~kg} \mathrm{ha}^{-1}$ da formulação 05-20-20 de $\mathrm{N}-\mathrm{P}_{2} \mathrm{O}_{5}-\mathrm{K}_{2} \mathrm{O}$. Utilizou-se esta formulação, com menor quantidade de $\mathrm{P}$ e $\mathrm{K}$, pelo fato de o resultado da análise de solo ter apresentado valores altos dos nutrientes nas camadas amostradas. A adubação de cobertura no estádio V4 foi de $100 \mathrm{~kg}$ de $\mathrm{N} \mathrm{ha}^{-1}$, conforme a análise de solo e a recomendação para a cultura nesta fase (Battisti et al., 2013).

Tanto na área da safra de 2011 como na área da safra de 2012, a semeadura foi realizada com uso da semeadora de parcelas experimentais Semina (Máquinas Agrícolas SB Ltda., Caxias do Sul, RS, Brasil) com as linhas ajustadas aos diversos espaçamentos. Utilizou-se o híbrido de canola Hyola 61, que apresenta resistência poligênica à canela-preta e ciclo de 123 a 160 dias. As sementes apresentaram poder germinativo de $90 \%$ e massa de mil sementes de $4,8 \mathrm{~g}$.

O delineamento experimental utilizado foi o de blocos ao acaso, com quatro repetições, em arranjo de parcelas subdivididas. As parcelas foram constituídas pelos espaçamentos entre linhas $(17,34,51,68 \mathrm{~cm})$ e, as subparcelas, pelas densidades de plantas $(15,30$, 45 e 60 plantas $\mathrm{m}^{-2}$ ), com o total de 64 subparcelas. O comprimento das subparcelas foi de cinco metros, e a largura variou em razão do espaçamento entre linhas - 136, 204, 204 e $272 \mathrm{~cm}$-, respectivamente, para os espaçamentos de 17, 34, 51, $68 \mathrm{~cm}$. Consideraram-se as linhas centrais como área útil da subparcela, tendo-

Pesq. agropec. bras., Brasília, v.48, n.10, p.1332-1341, out. 2013 DOI: 10.1590/S0100-204X2013001000004 
se eliminado as linhas de bordadura. $\mathrm{O}$ espaçamento foi de $50 \mathrm{~cm}$ entre parcelas e de um metro, entre blocos.

A dessecação da área ocorreu uma semana antes da semeadura, com $2 \mathrm{~L} \mathrm{ha}^{-1}$ do herbicida glifosato. Além disso, foi efetuado o controle da traça, principal praga para a família das Brassicaceae, com aplicação de $200 \mathrm{~mL} \mathrm{ha}^{-1}$ de metamidofós, no ano de 2011. Na safra de 2012, foram aplicados $2 \mathrm{~L} \mathrm{ha}^{-1}$ de glifosato à semeadura, além de 1,5 $\mathrm{L} \mathrm{ha}^{-1}$ do inseticida clorpirifos, para controle da vaquinha (Diabrotica speciosa L.), no período vegetativo da cultura. Também foram realizados os controles de Lolium multiflorum (L.), com aplicação do herbicida setoxidim a $1 \mathrm{~L} \mathrm{ha}^{-1}$, e de lagarta, no início da floração, com aplicação do inseticida tiametoxam e lambda-cialotrina a $200 \mathrm{~mL} \mathrm{ha}^{-1}$.
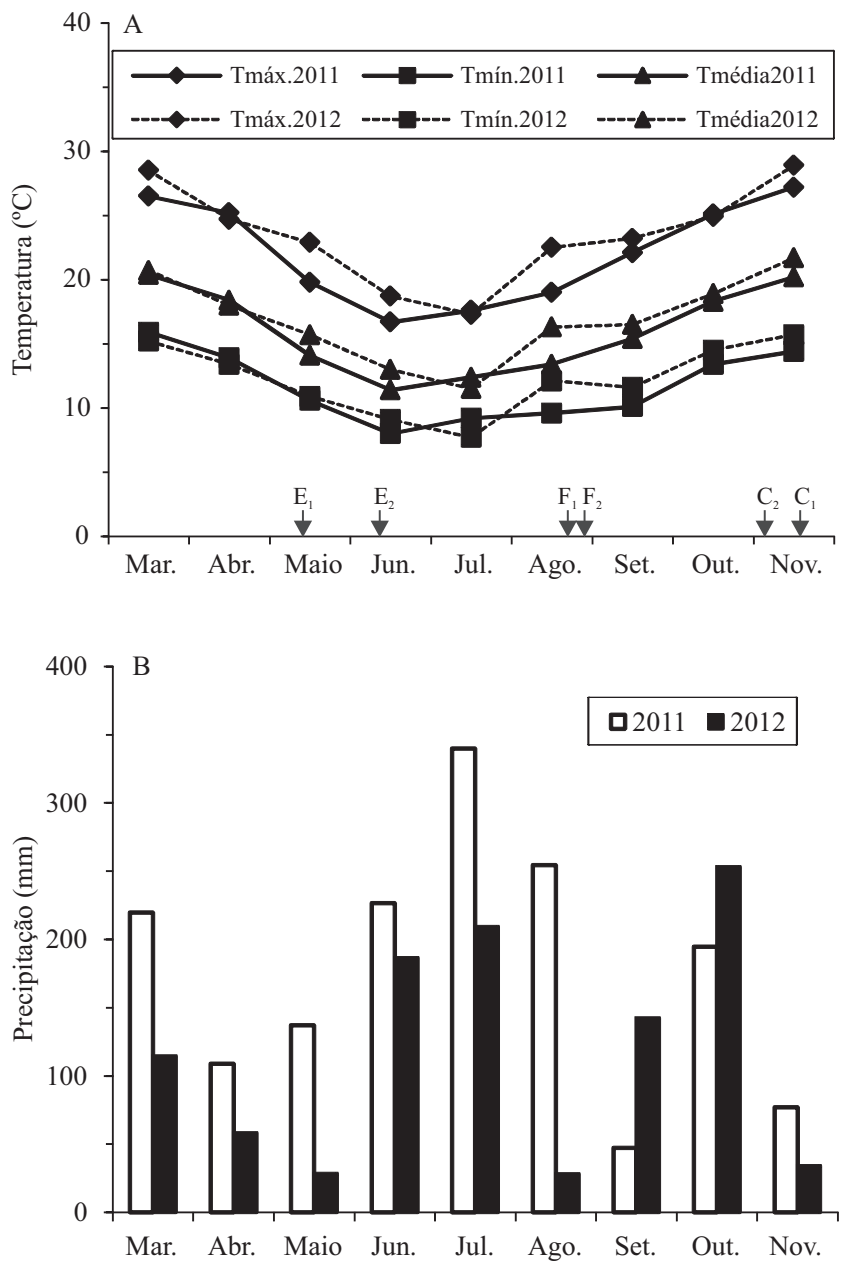

Figura 1. Temperatura (A) máxima (Tmáx.), média (Tmédia) e mínima (Tmín.) e precipitação pluvial (B) dos meses de cultivo da canola nos anos de 2011 e 2012. E, emergência; F, início da floração; C, colheita; 1,$2011 ; 2,2012$.
Quando as plantas apresentavam de quatro a cinco folhas verdadeiras, realizaram-se desbastes para ajustar a densidade desejada. O controle das plantas daninhas foi realizado com capina manual, principalmente de nabiça (Raphanus sativus L.), espécie da mesma família da canola e altamente competidora por nutrientes, água e luminosidade.

Para a caracterização do desenvolvimento de ramificações, coletaram-se aleatoriamente cinco plantas por subparcela das linhas centrais, as quais foram cortadas na haste principal mais próxima do solo, tendo-se deixado o sistema radicial. A coleta foi realizada quando as plantas atingiram seu ponto de maturação fisiológica, em que cerca de $30 \%$ dos grãos apresentavam-se com a cor marrom. Após a coleta das plantas, realizou-se, em laboratório, a avaliação das seguintes variáveis: número de ramos secundários (NRS), terciários (NRT) e quaternários (NRQ); número de síliquas nos ramos primários (NS1), secundários (NS2), terciários (NS3) e quaternários (NS4); número de síliquas por planta (NSP); e número de grãos por planta (NGP). Além disso, foram avaliados: o rendimento biológico aparente por planta (RBA, g); o rendimento de palha por planta (RP, g); o rendimento de grãos por planta (RGP, g); e o índice de colheita (IC, \%). As estruturas das plantas foram secas durante dois dias em estufa, a $65^{\circ} \mathrm{C}$ (Battisti et al., 2013).

Para a determinação da massa de mil grãos (MMG, g) e o rendimento de grãos ( $\left.\mathrm{RG}, \mathrm{kg} \mathrm{ha}^{-1}\right)$, realizou-se a colheita de todas as plantas presentes na subparcela, tendo-se eliminado a linha de bordadura, quando cerca de $50 \%$ dos grãos apresentavam-se com a cor marrom (Battisti et al., 2013). Em 2011, a colheita foi realizada no dia 21 de outubro e, em 2012, no dia 16 de outubro. A massa de grãos colhidos foi ajustada ao teor de umidade de $10 \%$.

Os dados obtidos foram submetidos à análise de variância e, quando houve diferenças significativas, realizou-se a análise de regressão pelos modelos lineares ou quadrático.

\section{Resultados e Discussão}

O aumento da densidade de plantas acarretou decréscimos lineares do número de ramos secundários, terciários e quaternários, nas plantas de canola, em 2011 (Figura 2). O número de ramos secundários, terciários e quaternários à densidade de 15 plantas 

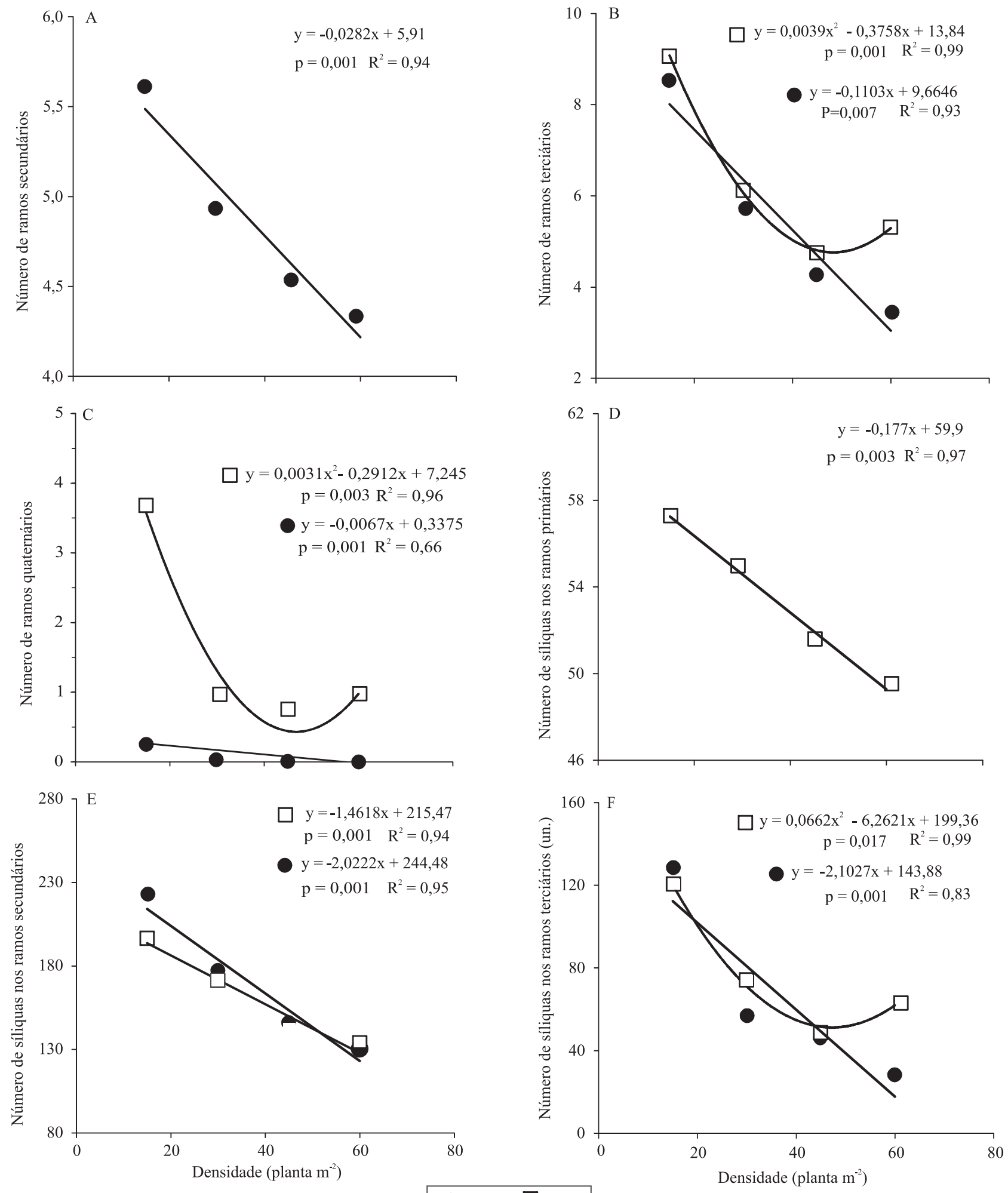

$2011 \square 2012$

Figura 2. Número de ramos secundários (A), número de ramos terciários (B), número de ramos quaternários (C), número de síliquas no ramo primário (D), número de síliquas nos ramos secundários (E) e número de síliquas nos ramos terciários $(\mathrm{F})$, em canola Hyola 61, em função da densidade de plantas nos anos de 2011 e 2012. 
$\mathrm{m}^{-2}$ foi de 5,62, 8,54 e 0,40, respectivamente, e à densidade de 60 plantas $\mathrm{m}^{-2}$ foi de 4,34, 3,52 e 0,30, respectivamente. Entre a menor e a maior densidade de plantas, houve redução de $23 \%$ do número de ramos secundários, $59 \%$ do número de ramos terciários e de $25 \%$ do número de ramos quaternários. Mousavi et al. (2011) avaliaram três densidades de plantas de canola e observaram resultado semelhante, pois à medida que aumentou a densidade de plantas o número de ramos por planta foi reduzido.

No ano de 2012, o número de ramos terciários e quaternários também foi reduzido com o aumento da densidade de plantas (Figura 2); este comportamento é mais bem explicado com o modelo quadrático. Nesse ano, houve maior número de ramos quaternários por planta $(\sim 4)$, à densidade de 15 plantas $\mathrm{m}^{-2}$, do que em $2011(0,32)$. Esta diferença, provavelmente, foi ocasionada pela escassez de água ocorrida no período de inverno (Figura 2), principalmente durante a germinação da canola, o que causou desuniformidade do estande inicial das plantas, com maior formação de ramos laterais por planta, principalmente quaternários, que variaram de um a quatro (Figura $2 \mathrm{C}$ ).

Quanto ao número de síliquas, no ano de 2011, observaram-se decréscimos lineares no número de síliquas dos ramos secundários e terciários, com o aumento da densidade de plantas (Figura 2). O número de síliquas dos ramos secundários e terciários obtidos à densidade de 15 plantas $\mathrm{m}^{-2}$ foi de 221,29 e 129,23, respectivamente e, à densidade de 60 plantas $\mathrm{m}^{-2}$, foi de 130,31 e 27,88, respectivamente. Entre a menor e a maior densidade de plantas, houve redução de $41,11 \%$ do número síliquas dos ramos secundários e 78,42\% do número de síliquas dos ramos terciários.

No ano de 2012, houve comportamento similar quanto ao número de síliquas dos ramos primários e secundários (Figura 2), porém, quanto ao número de síliquas dos ramos terciários e quaternários (Figura 3), o modelo que melhor explicou este comportamento foi o quadrático. Houve redução quanto ao número de síliquas por planta, à medida que aumentou a densidade de plantas, em ambos os anos. Em 2011, ocorreu decréscimo linear do número de síliquas por planta e, em 2012, o modelo que melhor explicou este comportamento foi o quadrático (Figura 3).

Em 2011, o número de síliquas por planta obtido à densidade de 15 plantas $\mathrm{m}^{-2}$ foi de 391 e à densidade de 60 plantas $\mathrm{m}^{-2}$ foi de 225 . Entre a menor e a maior densidade de plantas, houve redução de $42,71 \%$ desta variável (Figura $3 \mathrm{~B}$ ). A cada aumento de uma planta por metro quadrado, ocorreu a redução de 3,29 síliquas por planta. Krüger et al. (2011) avaliaram diferentes densidades de plantas $\left(20,40,60\right.$ e 80 plantas $\left.\mathrm{m}^{-2}\right)$ e, também, observaram que o número de síliquas por planta foi maior ao utilizar menores densidades. Resultado semelhante também foi verificado por Al-doori (2011) e Mousavi et al. (2011), que observaram que à medida que aumentou a densidade de plantas, diminuiu o número de síliquas por planta. Segundo Johnson \& Hanson (2003), uma cultura apresenta maior produtividade, quando tem distribuição uniforme, em razão do melhor aproveitamento de radiação solar no período vegetativo e da redução da competição entre as plantas, o que aumenta o número de síliquas por planta.

O número de grãos por planta diminuiu linearmente com o aumento na densidade de plantas, nos anos de 2011 e 2012 (Figura 3). Nos dois anos, o número de grãos por planta, obtidos à densidade de 15 plantas $\mathrm{m}^{-2}$, foi de 4.816 e 3.889, respectivamente e, à densidade de 60 plantas $\mathrm{m}^{-2}$, foi de 2.500 e 2.803 , respectivamente. Entre a menor e a maior densidade de plantas, houve redução de $48 \%$ do número de grãos por planta, no ano de 2011, e redução de 28\% no ano de 2012.

Durante o período vegetativo da cultura, em 2011, ocorreram precipitações acima da média, em junho (226,7 $\mathrm{mm})$, julho $(340 \mathrm{~mm})$ e agosto $(254,4 \mathrm{~mm})$, e temperaturas no mês de julho que variaram de -2 a $3^{\circ} \mathrm{C}$, durante seis dias consecutivos (Figura $1 \mathrm{~A}$ ), o que reduziu de forma acentuada o crescimento das plantas de canola. Em consequência, houve um período mais longo de formação de folhas, o que aumentou a captação de radiação solar e a atividade fotossintética. Consequentemente, a maior partição de fotoassimilados para as diferentes partes da planta é, provavelmente, uma explicação para a maior variação do número de grãos por planta, no ano de 2011, de 2.500 a 4.816 , em comparação aos 2.706 a 3.889 , em 2012, o que representa uma redução de $20 \%$ do total de grãos na safra de 2012.

Quanto ao rendimento biológico aparente por planta (Figura 3), observaram-se decréscimos lineares com o aumento da densidade de plantas. Nos anos de 2011 e 2012, o rendimento biológico aparente por planta, obtido à densidade de 15 plantas $\mathrm{m}^{-2}$, foi de 52,34 e 52,60, respectivamente, e à densidade de 60 plantas $\mathrm{m}^{-2}$, foi de 29,05 e 37,11 , respectivamente. 

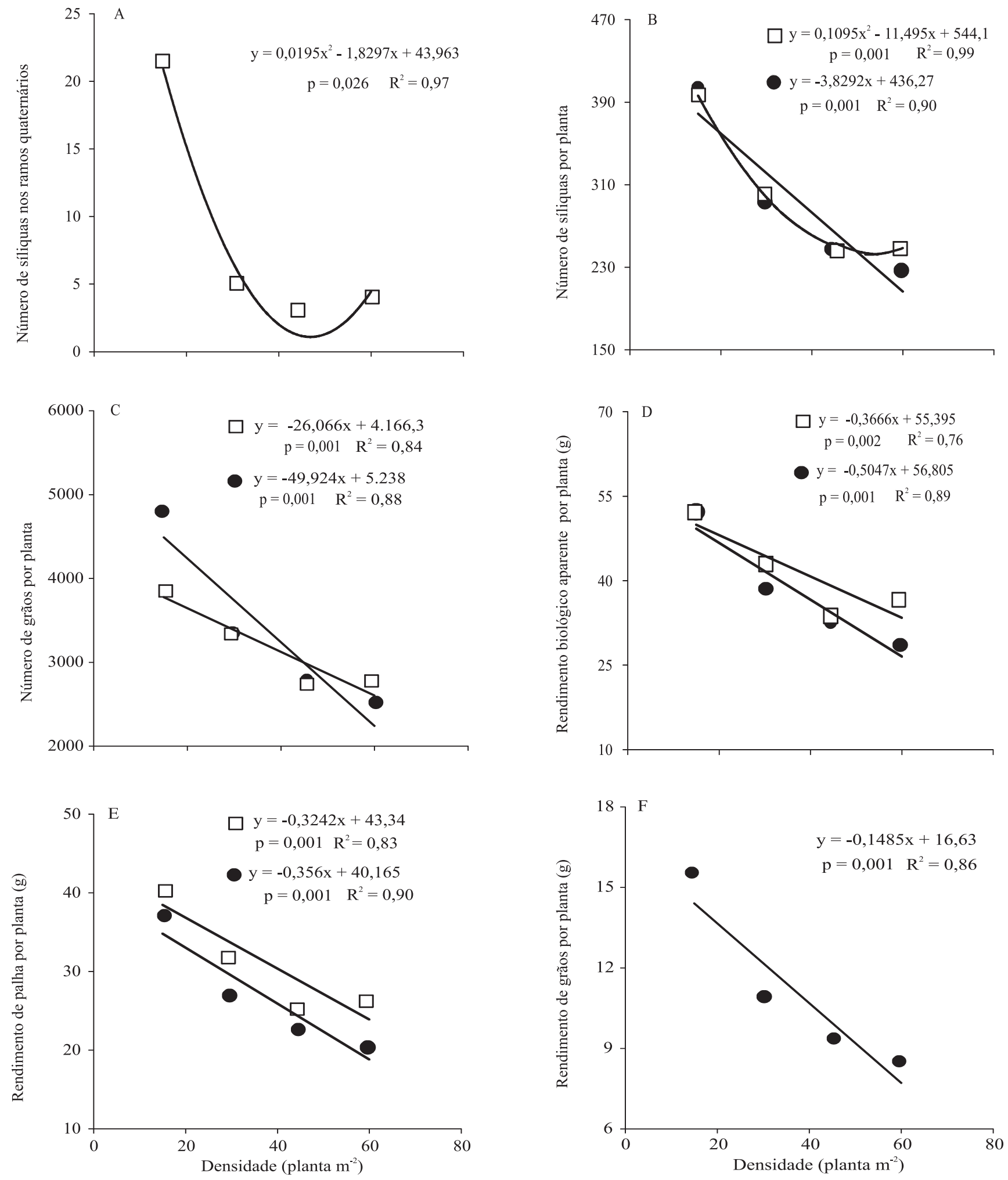

$2011 \square 2012$

Figura 3. Número de síliquas nos ramos quaternários (A), número de síliquas por planta (B), número de grãos por planta (C), rendimento biológico aparente por planta (D), rendimento de palha por planta (E) e rendimento de grãos por planta (F), em canola Hyola 61, em função da densidade de plantas nos anos de 2011 e 2012. 
Entre a menor e a maior densidade, houve redução de $44 \%$ do rendimento biológico aparente por planta no ano de 2011 , e $29 \%$ no ano de 2012 . Resultado semelhante foi obtido por Al-Doori (2011).

$\mathrm{O}$ rendimento de palha por planta apresentou decréscimos lineares com o aumento na densidade de plantas (Figura 3 E). Nos anos de 2011 e 2012, o rendimento de palha por planta, obtido à densidade de 15 plantas $\mathrm{m}^{-2}$, foi de 36,85 e 40,57, respectivamente, e à densidade de 60 plantas $\mathrm{m}^{-2}$, foi de 20,47 e 26,54, respectivamente. Entre a menor e a maior densidade de plantas, houve redução de $44 \%$ do rendimento de palha, no ano de 2011, e 34\% no ano de 2012.

O rendimento de palha por planta é uma variável de extrema importância para o sistema de plantio direto, pois a canola possui relação $\mathrm{C} / \mathrm{N}$ baixa, ou seja, o processo de decomposição de sua resteva é rápido, com pronto retorno dos nutrientes ao solo e, assim, para as culturas subsequentes. No entanto, em culturas como a soja, a decomposição da resteva de canola pode acarretar alelopatia, em razão da liberação de compostos tóxicos (Battisti et al., 2013).

Quanto ao rendimento de grãos por planta, no ano de 2011, observou-se redução linear com o aumento da densidade de plantas. O rendimento de grãos por planta, obtido à densidade de 15 plantas $\mathrm{m}^{-2}$, foi de $15,48 \mathrm{~g}$, e a 60 plantas $\mathrm{m}^{-2}$, foi de $8,58 \mathrm{~g}$. Entre a menor e a maior densidade de plantas, houve redução de $44 \%$ do rendimento de grãos por planta, ou seja, a cada aumento de uma planta por metro quadrado, houve uma redução de aproximadamente $0,15 \mathrm{~g}$ do rendimento de grãos (Figura $3 \mathrm{~F}$ ).

No ano de 2012, o rendimento de grãos por área obtido à densidade de 15 plantas $\mathrm{m}^{-2}$ foi de $754,80 \mathrm{~kg} \mathrm{ha}^{-1}$ e à densidade de 60 plantas $\mathrm{m}^{-2}$ foi de $931,61 \mathrm{~kg} \mathrm{ha}^{-1}$. Entre a menor e a maior população de plantas, houve acréscimo de $23 \%$ do rendimento de grãos, ou seja, à medida que aumentou uma planta por metro quadrado, houve aumento de $4,09 \mathrm{~kg} \mathrm{ha}^{-1} \mathrm{do}$ rendimento (Figura $4 \mathrm{~B}$ ).

Quanto ao efeito do espaçamento entre linhas, no ano de 2012, o número de síliquas por planta aumentou linearmente à medida que aumentou o espaçamento (Figura 5). O número de síliquas por planta, obtido no espaçamento de $17 \mathrm{~cm}$, foi de 271,62, e no de $68 \mathrm{~cm}$ entre linhas, foi de 339,75. Entre o menor e o maior espaçamento entre linhas, houve acréscimo de 25,08\% do número de síliquas por planta (Figura 5 B). A cada aumento de um centímetro no espaçamento entre linhas, ocorreu acréscimo de 1,54 síliquas por planta.

Foram observados acréscimos lineares no número de síliquas dos ramos terciários com o aumento no espaçamento entre linhas. O número de síliquas nesses ramos, no espaçamento de $17 \mathrm{~cm}$, foi de 59,68 e, no de $68 \mathrm{~cm}$, foi de 97,37. Entre o menor e o maior espaçamento utilizado, houve um acréscimo de $63,15 \%$ no número de síliquas dos ramos terciários (Figura 5 A). A cada aumento de um centímetro no espaçamento entre linhas, houve acréscimo de 0,87 síliquas nos ramos terciários.

Observou-se um decréscimo linear da massa de mil grãos, no ano de 2012, com o aumento no espaçamento entre linhas (Figura 5). A massa de mil grãos, obtida no espaçamento de $17 \mathrm{~cm}$ entre linhas, foi de $3,3 \mathrm{~g} \mathrm{e}$, no de $68 \mathrm{~cm}$, foi de 2,9 g. Entre o menor e o maior espaçamento entre linhas houve redução de $12 \%$. A cada aumento de um centímetro no espaçamento entre linhas, houve redução aproximada de $0,008 \mathrm{~g}$ da massa de mil grãos.

Ao avaliar diferentes cultivares de canola, com espaçamento de $30 \mathrm{~cm}$ entre linhas, Inayt-Ur-Rahmann et al. (2009) observaram variação da massa de mil grãos de 3,17 a 2,55 g, valores próximos aos obtidos no presente trabalho. No entanto, Krüger et al. (2011) não verificaram diferenças significativas para esta variável, em diferentes espaçamentos entre plantas, tendo obtido médias de 3,4 e 3,8 g, respectivamente, no primeiro e segundo anos de avaliação.

O rendimento de grãos por área, no ano de 2011, apresentou redução linear, à medida que aumentou o espaçamento entre linhas. $\mathrm{O}$ rendimento de grãos por área, obtido no espaçamento de $17 \mathrm{~cm}$, foi de $1.041,32 \mathrm{~kg} \mathrm{ha}^{-1} \mathrm{e}$, no de $68 \mathrm{~cm}$, foi de $576,75 \mathrm{~kg} \mathrm{ha}^{-1}$. Entre o menor e o maior espaçamento, houve redução de $45 \%$ do rendimento de grãos, ou seja, à medida que aumentou um centímetro no espaçamento entre linhas, houve redução de $10,78 \mathrm{~kg}$ do rendimento de grãos (Figura 4 A).

$\mathrm{O}$ rendimento de grãos, na média nacional obtida em 2011 (1.226 kg ha-1) e 2012 (1.249 kg ha $\left.{ }^{-1}\right)$, segundo levantamentos da Companhia Nacional do Abastecimento (2012), apresentou valores um pouco mais elevados do que os do presente trabalho. Isto pode ser atribuído às perdas de grãos pelo excesso de chuvas, no fim do ciclo e na colheita em 2011 (Figura 1 B), e às perdas por deiscência das síliquas, pela ocorrência de geada em 26 de setembro de 2012, com temperatura 
mínima de $0,5^{\circ} \mathrm{C}$ (Figura $1 \mathrm{~A}$ ), o que causou secagem das síliquas, da parte mediana até o ápice das plantas e antecipação da colheita.

O maior rendimento de grãos de canola (2.600 $\mathrm{kg} \mathrm{ha}^{-1}$ ), em comparação ao do presente trabalho, foi obtido por Chavarria et al. (2011), ao utilizar espaçamento de $17 \mathrm{~cm}$ e densidade de 45 plantas $\mathrm{m}^{-2}$. Bagheri et al. (2011), ao trabalhar com diferentes espaçamentos $(15,30$ e $45 \mathrm{~cm})$ e densidades $\left(5,10\right.$ e 15 plantas $\left.\mathrm{m}^{-2}\right)$, observaram que o espaçamento de $15 \mathrm{~cm}$ foi o que resultou em maior produtividade
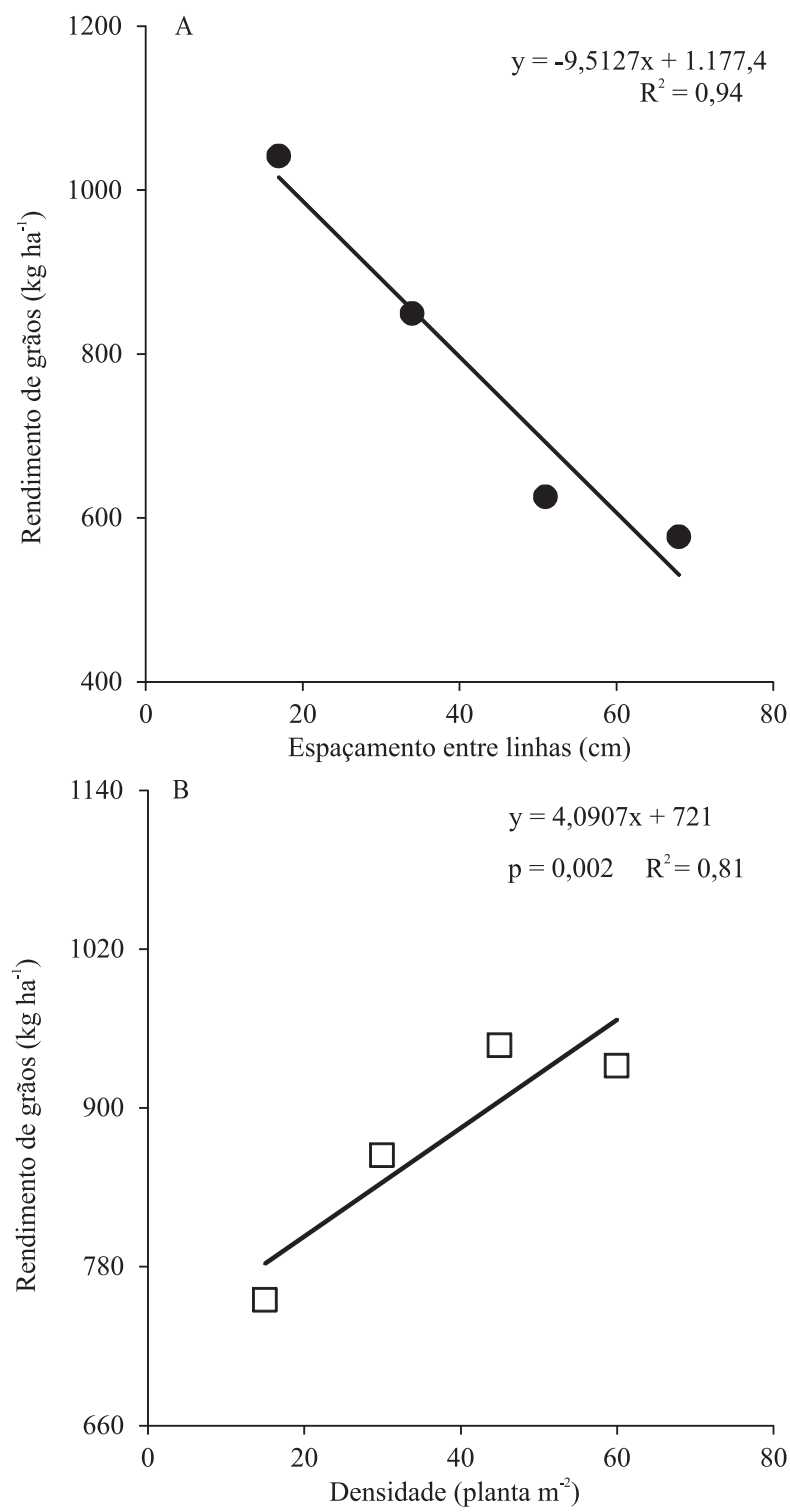

Figura 4. Rendimento de grãos de canola, em função do espaçamento entre linhas, no ano de 2011 (A), e da densidade de plantas, no ano de 2012 (B).
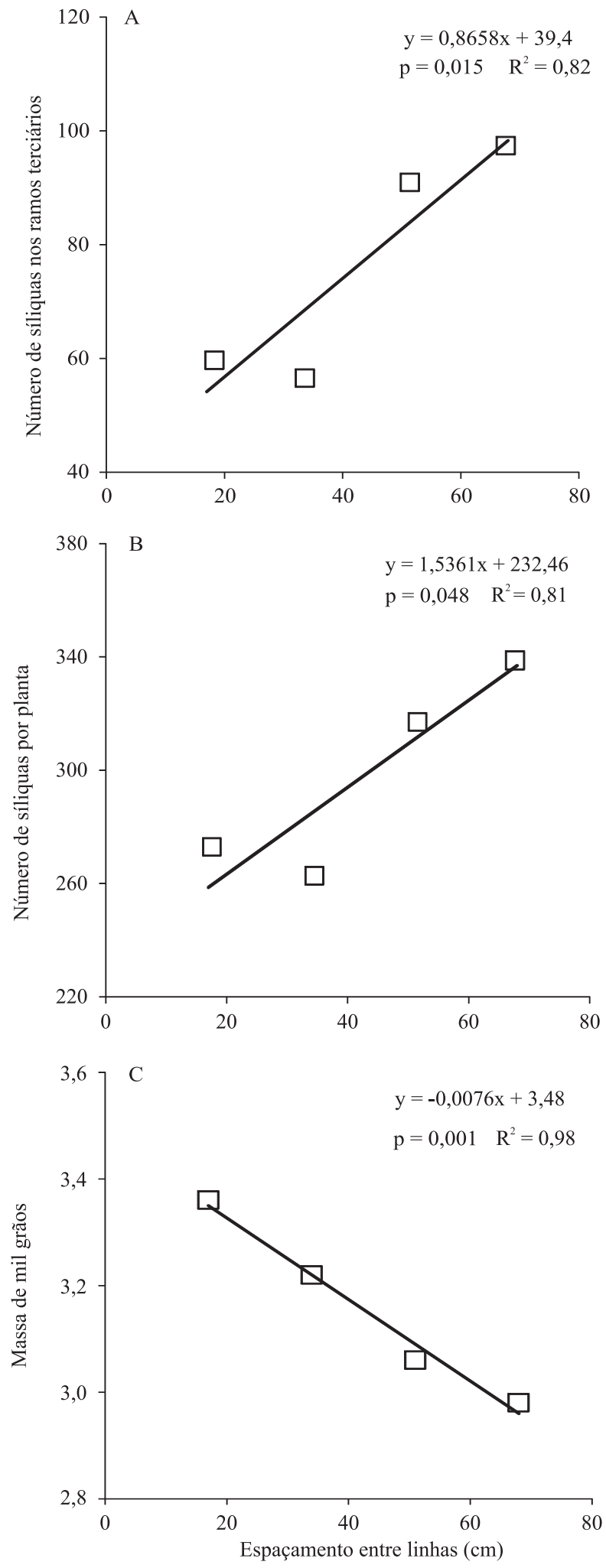

Figura 5. Número de síliquas nos ramos terciários (A), número de síliquas por planta (B) e massa de mil grãos (C), em canola, em função do espaçamento entre linhas, no ano de 2012.

Pesq. agropec. bras., Brasília, v.48, n.10, p.1332-1341, out. 2013 DOI: 10.1590/S0100-204X2013001000004 
(1.195 $\left.\mathrm{kg} \mathrm{ha}^{-1}\right)$; porém, estes autores não detectaram diferenças decorrentes das densidades. Krüger et al. (2011) também verificaram que a maior produtividade (1.381 $\mathrm{kg} \mathrm{ha}^{-1}$ ) foi obtida ao se utilizar menor espaçamento ( $20 \mathrm{~cm}$ entre linhas), e que variações de densidade não influenciaram o rendimento de grãos.

Em um trabalho realizado em cinco localidades no Sul do Brasil, Santos et al. (1990) observaram aumento do rendimento de grãos, com a diminuição do espaçamento e da densidade de semeadura, com maior produtividade no espaçamento de $18 \mathrm{~cm}$ entre linhas, associado a $3 \mathrm{~kg} \mathrm{ha}^{-1}$ de sementes, o que equivale à densidade aproximada de até 40 plantas $\mathrm{m}^{-2}$.

Geralmente, os espaçamentos recomendados para a cultura da canola estão na faixa de 20 a $40 \mathrm{~cm}$ entre linhas, a densidades de semeadura entre 3,0 a $6,0 \mathrm{~kg} \mathrm{ha}^{-1}$ (40 a 80 plantas $\mathrm{m}^{-2}$ ) (Dias, 1992). No entanto, culturas testadas com espaçamentos menores do que $20 \mathrm{~cm}$ e populações menores do que $3,0 \mathrm{~kg} \mathrm{ha}^{-1}$ apresentaram produtividade de grãos mais elevada. Porém, estas indicações somente devem ser praticadas em condições de disponibilidade de sementes de alta qualidade e equipamento de semeadura adequado (Dias, 1992).

Nas condições ambientais brasileiras, é importante empregar espaçamento de até $45 \mathrm{~cm}$ e um número mínimo de 40 plantas $\mathrm{m}^{-2}$, para se assegurar um bom potencial de rendimento (Battisti et al., 2013). Entretanto, com os resultados do presente trabalho, mostra-se que a utilização de espaçamentos reduzidos até o máximo de $34 \mathrm{~cm}$ entre linhas, com população máxima de 45 plantas $\mathrm{m}^{-2}$, poderá ser vantajosa.

\section{Conclusões}

1. A densidade de plantio de 15 plantas por metro quadrado é a que propicia maior número de ramos, maior número de síliquas por planta, maior número de grãos por planta e maior produção de massa total da planta.

2. O maior rendimento de grãos por área é obtido em espaçamento de $17 \mathrm{~cm}$ entre linhas, à densidade de 45 plantas por metro quadrado.

\section{Referências}

AL-DOORI, S.A.M. A study of the importance of sowing dates and plant density affecting some rapeseed cultivars (Brassica napus L.). College of Basic Education Researchers Journal, v.11, p.615-632, 2011.
ARGENTA, G.; SILVA, P.R.F. da; SANGOI, L. Arranjo de plantas em milho: análise do estado-da-arte. Ciência Rural, v.31, p.1075-1084, 2001. DOI: 10.1590/S0103-84782001000600027.

BAGHERI, H.; SHARGHI, Y.; YAZDANI, M. The study of planting density on some agronomic traits of spring canola cultivars. Australian Journal of Basic and Applied Sciences, v.5, p.1302-1305, 2011.

BATTISTI, R.; PILAU, F.G.; SCHWERZ, L.; SOMAVILLA, L. ; TOMM, G.O. Dinâmica floral e abortamento de flores em híbridos de canola e mostarda castanha. Pesquisa Agropecuária Brasileira, v.48, p.174-181, 2013. DOI: 10.1590/S0100-204X2013000200007.

CANOLA COUNCIL OF CANADA. History of the canola plant. 2012. Available at: <http://www.canolainfo.org/canola/index. php?page $=5>$. Accessed on: 6 Nov. 2012.

CHAVARRIA, G.; TOMM, G.O.; MULLER, A.; MENDONÇA, H.F.; MELLO, N.; BETTO, M.S. Índice de área foliar em canola cultivada sob variações de espaçamento e de densidade de semeadura. Ciência Rural, v.41, p.2084-2089, 2011. DOI: 10.1590/S0103-84782011001200008.

COMPANHIA NACIONAL DO ABASTECIMENTO. Acompanhamento da safra brasileira - grãos - safra 2011/2012 - décimo segundo levantamento - janeiro/2012. Brasília: Conab, 2012. 8p.

DIAS, J.C.A. Canola/colza: alternativa de inverno com perspectiva de produção de óleo comestível e combustível. Capão do Leão: Embrapa-CPATB, 1992. 46p. (Embrapa-CPATB. Boletim de pesquisa, 3).

GAN, Y.; ANGADI, S.V.; CUTFORTH, H.; POTTS, D.; ANGADI, V.V.; MCDONALD, C.L. Canola and mustard response to short periods of temperature and water stress at different developmental stages. Canadian Journal of Plant Science, v.84, p.697-704, 2004. DOI: 10.4141/P03-109.

INAYT-UR-RAHMAN; AHMAD, H.; INAMULLAH; SIRAJUDDIN; AHMAD, I.; ABBASI, F.M.; ISLAM, M.; GHAFOOR, S. Evaluation of rapeseed genotypes for yield and oil quality under rainfed conditions of district Mansehra. African Journal of Biotechnology, v.8, p.6844-6849, 2009.

JOHNSON, B.L.; HANSON, B.K. Row-spacing interactions on spring canola performance in the Northern Great Plains. Agronomy Journal, v.95, p.703-708, 2003. DOI: 10.2134/ agronj2003.0703.

KRÜGER, C.A.M.B.; SILVA, J.A.G. da; MEDEIROS, S.L.P.; DALMAGO, G.A.; SARTORI, C.O.; SCHIAVO, J. Arranjo de plantas na expressão dos componentes da produtividade de grãos de canola. Pesquisa Agropecuária Brasileira, v.46, p.1448-1453, 2011. DOI: 10.1590/S0100-204X2011001100005.

MOUSAVI, S.J.; SAM-DALIRI, M.; BAGHERI, H. Study of planting density on some agronomic traits of rapeseed three cultivar (Brassica napus L.). Australian Journal of Basic and Applied Sciences, v.5, p.2625-2627, 2011.

SANTOS, H.G. dos; JACOMINE, P.K.T.; ANJOS, L.H.C. dos; OLIVEIRA, V.A. de; OLIVEIRA, J.B. de; COELHO, M.R.; LUMBRERAS, J.F.; CUNHA, T.J.F. (Ed.). Sistema brasileiro de classificação de solos. 2.ed. Rio de Janeiro: Embrapa Solos, 2006. $306 \mathrm{p}$. 
SANTOS, H.P. dos; LHANBY, J.C.B.; DIAS, J.C.A. Efeito do espaçamento e da densidade de semeadura sobre o comportamento agronômico da colza. Pesquisa Agropecuária Brasileira, v.25, p.701-707, 1990.

TAN, X.-L.; KONG, F.-M.; ZHANG, L.-L.; LI, J.; CHEN, S.; QI, C.-K. Cloning and analysis of hemoglobin gene in
Cyanobacterium and transformation into Brassica napus (L.). Acta Agronomica Sinica, v.35, p.66-70, 2009. DOI: 10.1016/ S1875-2780(08)60055-3.

TOMM, G.O. Canola. Passo Fundo: Embrapa Trigo, 2013. Disponível em: <http://sistemasdeproducao.cnptia.embrapa.br/ FontesHTML/Canola/CultivodeCanola/> . Acesso em: 16 abr. 2013.

Recebido em 17 de junho de 2013 e aprovado em 13 de setembro de 2013 